\title{
Changes in diet and physical activity prevented type 2 diabetes mellitus in people with impaired glucose tolerance
}

Tuomilehto J, Lindström J, Eriksson JG, et al, for the Finnish Diabetes Prevention Study Group. Prevention of type 2 diabetes mellitus by changes in lifestyle among subjects with impaired glucose tolerance. N Engl J Med 2001 May 3;344:1343-50.

\section{QUESTION: In patients with impaired glucose tolerance, is a lifestyle intervention programme effective for preventing type 2 diabetes mellitus?}

\section{Design}

Randomised (allocation concealed*), unblinded,* controlled trial with mean follow up of 3.2 years (the Finnish Diabetes Prevention Study).

\section{Setting}

5 locations in Finland (Helsinki, Kuopio, Oulu, Tampere, and Turku).

\section{Patients}

522 patients between 40 and 65 years of age (mean age 55 y, 67\% women) who were overweight (body mass index $\geqslant 25 \mathrm{~kg} / \mathrm{m}^{2}$ ) and had impaired glucose tolerance (mean plasma glucose level between 7.8 and 11.0 mmol/l $2 \mathrm{~h}$ after receiving $75 \mathrm{~g}$ of oral glucose on 2 occasions, in patients with plasma glucose levels $<7.8$ $\mathrm{mmol} / \mathrm{l}$ after an overnight fast). Exclusion criteria included diabetes mellitus and advanced chronic disease. Follow up was $92 \%$.

\section{Intervention}

Patients were allocated to receive individualised counselling aimed at reducing weight by $\geqslant 5 \%$, reducing total and saturated fat intake, increasing intake of fibre, and increasing physical activity to at least 30 minutes per day (intervention group, $\mathrm{n}=265$ ) or general oral and written information about diet and exercise (control group, $\mathrm{n}=257$ )

\section{Main outcome measures}

The primary outcome measure was incidence of newly diagnosed type 2 diabetes (confirmed by 2 oral glucose tolerance tests). A secondary outcome measure was amount of weight loss.

Sources of funding:

Finnish Academy;

Ministry of Education;

Nowo Nordisk

Foundation; Yrjö

Jahnsson Foundation;

Finnish Diabetes

Research Foundation.

For correspondence: Professor J Tuomilehto, National Public Health Institute, Department of Epidemiology and Health Promotion, Diabetes and Genetic Epidemiology Unit, Mannerheimintie 166, FIN-00300 Helsinki, Finland. Fax +3589 47448338.

\section{Main results}

Analysis was by intention to treat. At 2 years, people in the intervention group had a greater mean weight loss than did those in the control group (3.5 $v 0.8 \mathrm{~kg}, \mathrm{p}<$ $0.001)$. At 4 years, the incidence of diabetes was lower in the intervention group than in the control group $(\mathrm{p}<$ 0.001 ) (table).

\section{Conclusion}

An individualised lifestyle intervention programme aimed at improving dietary habits and increasing physical activity was effective for preventing type 2 diabetes mellitus in people with impaired glucose tolerance.

*See glossary.
Lifestyle intervention programme $v$ control for the prevention of type 2 diabetes mellitus in patients with impaired glucose tolerance at a mean follow up of 3.2 yearst

\begin{tabular}{|c|c|c|c|c|}
\hline Outcome & $\begin{array}{l}\text { Lifestyle } \\
\text { intervention }\end{array}$ & Control & RRR $(95 \%$ Cl) & NNT (Cl) \\
\hline Diabetes & $10 \%$ & $23 \%$ & $56 \%$ (33 to 71$)$ & 8 (5 to 15$)$ \\
\hline
\end{tabular}

\section{COMMENTARY}

People who have a family history of type 2 diabetes, gestational diabetes, or signs of metabolic syndrome (ie, abdominal obesity, hypertriglyceridemia, or impaired fasting glucose) are at high risk for developing type 2 diabetes. A 6 year randomised trial done in China ${ }^{2}$ suggests that diet and exercise may decrease the risk for diabetes in these patients. In practice, some patients do not start or sustain these non-pharmacological interventions, and clinicians are usually sceptical about the efficacy of lifestyle modification interventions. Consequently, researchers are also evaluating medications (eg, acarbose, metformin, and angiotensinconverting enzyme inhibitors) that may prevent or delay the development of diabetes.

The study by Tuomilehto $e t$ al offers evidence for the sustained effectiveness of an intensive dietary and exercise intervention in patients with impaired glucose tolerance. This evidence is weakened by the lack of blinding of investigators. Furthermore, the intervention may not be as effective in usual practice because of differences that may exist between the volunteer participants and usual patients, and because of the inability of usual practice systems to provide intensive and individualised dietary and exercise interventions.

Nevertheless, clinicians should not be overly sceptical about their ability to modify a patient's lifestyle. This study suggests that such goals may not need to be ambitious to be effective. Patients who are at high risk for diabetes may benefit from intensive and individualised diet, and at-risk patients should collaborate with their physicians in establishing exercise programmes.

Victor Montori, MD Mayo Clinic Rochester, Minnesota, USA

1 Mahon J, Dupre J. Early detection and prevention of diabetes mellitus. In: Gerstein HC, Haynes RB, eds. Evidence-based Diabetes Care. Hamilton, Ontario, Canada: BC Decker, 2001.

2 Pan XR, Li GW, Hu YH, et al. Effects of diet and exercise in preventing NIDDM in people with impaired glucose tolerance. The Da Qing IGT and Diabetes Study. Diabetes Care 1997;20:537-44. 